\title{
Consumption of fructo-oligosaccharide reduces 2,4-dinitrofluorobenzene- induced contact hypersensitivity in mice
}

\author{
Jun Watanabe ${ }^{1}$, Naho Sasajima ${ }^{2}$, Akiko Aramaki $^{2}$ and Kei Sonoyama ${ }^{2} *$ \\ ${ }^{1}$ Creative Research Initiative 'Sousei', Hokkaido University, Sapporo 001-0021, Japan \\ ${ }^{2}$ Laboratory of Food Biochemistry, Division of Applied Bioscience, Graduate School of Agriculture, Hokkaido University, \\ Kita-9, Nishi-9, Kita-ku, Sapporo shi 060-8589, Japan
}

(Received 4 June 2007 - Revised 13 November 2007 - Accepted 14 November 2007 - First published online 15 January 2008)

Strategies to manipulate the intestinal microbiota have been considered to promote immune health. The aim of the present study was to examine whether fructo-oligosaccharide, a typical prebiotic, could suppress antigen-specific skin inflammation by favourably changing the population of intestinal microbiota. Female BALB/c mice were fed a synthetic diet with or without fructo-oligosaccharide supplementation for 3 weeks and were then epicutaneously immunised with 2,4-dinitrofluorobenzene. Afterwards, mice continued to receive their respective diets. At $5 \mathrm{~d}$ after immunisation, the mice were ear challenged with the hapten. Ear swelling after the challenge was significantly reduced in the mice fed the diet supplemented with fructo-oligosaccharide than in mice fed the control diet. To characterise the change in the intestinal microbiota, DNA samples isolated from fresh faeces were subjected to PCR-denaturing gradient gel electrophoresis and real-time PCR based on 16S rDNA gene sequences. Dietary fructo-oligosaccharide altered the composition of intestinal microbiota. The numbers of bifidobacteria, but not lactobacilli, were significantly higher in mice fed the fructo-oligosaccharide-supplemented diet than in mice fed the control diet. Ear swelling was negatively correlated with the numbers of bifidobacteria in the faeces. Sequence analysis revealed that Bifidobacterium pseudolongum was the most predominant bifidobacteria in the intestine of mice fed the fructo-oligosaccharide-supplemented diet. These results suggest that consumption of fructo-oligosaccharide reduces contact hypersensitivity, which is associated with proliferation of B. pseudolongum in the intestinal tract of mice.

Prebiotics: Intestinal microbiota: Contact hypersensitivity: Mice

Allergic contact dermatitis is one of the most prevalent human skin diseases, causing moderate to severe inflammatory damage. This pathological condition arises after contact hypersensitivity $(\mathrm{CHS})^{(1)}$. CHS is a T cell-mediated, antigenspecific type of skin inflammation that is induced by topical skin contact with haptens in a previously sensitised host ${ }^{(2,3)}$. When the host is sensitised by application of the hapten, skin dendritic cells capture the hapten and migrate to draining lymph nodes, where they prime specific $\mathrm{T}$ cells. These cells differentiate into CHS effector cells, which recirculate through the blood. The second contact with the same hapten leads to a skin inflammatory response that peaks $24-48 \mathrm{~h}$ after challenge. Avoidance of causal allergens is one of the emphasised therapeutic suggestions for CHS; however, avoidance is not practical in the majority of cases.

2,4-Dinitrofluorobenzene (DNFB) ${ }^{(4)}$, picryl chloride ${ }^{(5)}$ and oxazolone $^{(6)}$ have been used as typical haptens, which induce CHS in animals. DNFB-induced CHS in mice is the most widely used animal model for allergic contact dermatitis. In this model, mice are sensitised by application of DNFB onto shaved skin and are ear challenged by application of DNFB. Maximal ear swelling is observed $24-48 \mathrm{~h}$ after challenge.
Some food components, such as $\mathrm{DHA}^{(7)}$, glycyrrhizin ${ }^{(8)}$ and porphyran $^{(9)}$ reportedly suppressed DNFB-induced CHS in mice. Chapat et al. ${ }^{(4)}$ reported that oral administration of probiotic Lactobacillus casei reduced the DNFB-induced CHS response in mice.

Approximately 400 different microbial species, mostly bacteria, inhabit the intestinal tract of mammals, where the bacterial density reaches more than $10^{11}$ cells/g contents ${ }^{(10)}$. Commensal bacteria in the intestinal tract play a major role in the maturation of the immune system, maintenance of homeostasis of the gut-associated immune system ${ }^{(11-13)}$ and induction of oral tolerance ${ }^{(14-16)}$. Therefore, strategies to manipulate the microbiota have been considered to promote immune health. Some bacteria, such as the Lactobacillus and Bifidobacterium species, which have been described as 'living micro-organisms exerting health benefits', illustrate the concept of probiotics ${ }^{(17)}$. These bacteria prevent and treat rotavirus infections and post-antibiotic diarrhoea ${ }^{(18,19)}$, allergic diseases ${ }^{(20-22)}$ and recurrence of inflammatory bowel disease ${ }^{(23,24)}$.

Prebiotics are indigestible oligosaccharides that possess positive health outcomes through promoting colonisation of the gastrointestinal tract with beneficial bacteria ${ }^{(25)}$. In addition, some

Abbreviations: BSA, bovine serum albumin; CHS, contact hypersensitivity; DGGE, denaturing gradient gel electrophoresis; DNFB, 2,4-dinitrofluorobenzene; FOS, fructo-oligosaccharides.

* Corresponding author: Dr Kei Sonoyama, fax +81 11706 2496, email ksnym@chem.agr.hokudai.ac.jp 
indigestible oligosaccharides reportedly ameliorate allergic airway eosinophilia at least partly via post-absorptive mechanisms ${ }^{(26,27)}$. Stepans et al. ${ }^{(28)}$ reported that consumption of human milk oligosaccharides is inversely related to subsequent risk of respiratory and enteric diseases in infants. Growth of intestinal bifidobacteria can be stimulated by dietary supplementation with prebiotics ${ }^{(29)}$. For example, fructo-oligosaccharides (FOS), which are non-digestible polymers of fructose found naturally in artichokes, leeks, asparagus, onions and bananas, stimulate the growth of faecal bifidobacteria in healthy human subjects $^{(30-32)}$ and in mice ${ }^{(33)}$. Therefore, we postulated that dietary FOS may reduce the CHS response by stimulating the growth of intestinal bifidobacteria.

\section{Materials and methods}

\section{Animals and diets}

Female BALB/c mice (age 5 weeks) were purchased from Japan SLC (Hamamatsu, Japan) and housed in standard plastic cages in a temperature-controlled $\left(23 \pm 2^{\circ} \mathrm{C}\right)$ room with a dark period from 20.00 to 08.00 hours. They were allowed free access to food and water. Mice were allocated to two groups of six or seven mice and fed either a synthetic diet prepared according to AIN-93G ${ }^{(34)}$ or the diet supplemented with FOS (Meioligo P; Meiji Foodmateria, Tokyo, Japan). These diets were referred to as FOS( $(-)$ and $\mathrm{FOS}(+)$, respectively. The FOS $(+)$ diet was prepared by adding $50 \mathrm{~g}$ FOS to each $\mathrm{kg}$ of the $\operatorname{FOS}(-)$ diet by substituting FOS for $\alpha$-maize starch. Mice were fed the test diets for 3 weeks. Then, fresh faeces were collected, and CHS was induced as described below. At $12 \mathrm{~d}$ after DNFB immunisation, mice were anaesthetised by inhalation of diethyl ether, and blood was drawn from the carotid artery. In a separate experiment, female BALB/c mice (age 5 weeks) purchased from Japan Charles River (Yokohama, Japan) were used, and CHS responses and numbers of faecal bifidobacteria were determined.

The present study was approved by the Hokkaido University Animal Use Committee, and animals were maintained in accordance with the Hokkaido University guidelines for the care and use of laboratory animals.

\section{Induction of contact hypersensitivity}

CHS to DNFB was induced as previously described ${ }^{(4)}$. Briefly, mice were immunised on day 0 by epicutaneous application of $0.5 \%$ DNFB (Tokyo Kasei, Tokyo, Japan) in $25 \mu$ l acetoneolive oil $(4: 1, v / v)$ onto the shaved abdomen. On day 5 , mice were challenged with $0.25 \%$ DNFB in $8 \mu$ l acetone-olive oil $(4: 1, v / v)$ applied onto the right ear pinna, while $8 \mu$ l acetoneolive oil $(4: 1, \mathrm{v} / \mathrm{v})$ without DNFB was applied onto the left ear pinna. Ear thickness was measured with a digital engineer's micrometer (Mitsutoyo, Kawasaki, Japan) before challenge and 24, 48, 72 and $96 \mathrm{~h}$ after challenge. The ear thickness measurements were made by an investigator who was blinded to the treatments of the mice. DNFB-specific ear swelling was calculated according to the following equation:

$$
\begin{aligned}
\text { net swelling }= & (\text { right ear thickness }- \text { left ear thickness })_{24 \mathrm{~h}} \\
& -(\text { right ear thickness }- \text { left ear thickness })_{0 \mathrm{~h}} .
\end{aligned}
$$

The same equation was used for CHS measurements at 48, 72 and $96 \mathrm{~h}$ after the challenge.

\section{Antibody enzyme-linked immunosorbent assay}

Serum levels of IgG1 and IgG2a specific to the hapten were determined by ELISA. All assays were performed in ninetysix-well microtitre plates (Becton Dickinson, Franklin Lakes, NJ, USA). Wells were coated overnight at $4^{\circ} \mathrm{C}$ with dinitrophenol-bovine serum albumin (BSA; Calbiochem, San Diego, CA, USA) diluted to $30 \mu \mathrm{g} / \mathrm{ml}$ in carbonate buffer ( $\mathrm{pH}$ 9.6). Plates were blocked with PBS containing $2 \%$ BSA at $37^{\circ} \mathrm{C}$ for $1 \mathrm{~h}$. Serial dilutions of serum were prepared in PBS containing $0.2 \%$ BSA and $0.02 \%$ Tween-20 (PBS/ BSA-Tween) and then incubated for $2 \mathrm{~h}$ at room temperature. After the incubation, horseradish peroxidase-conjugated rat anti-mouse IgG1 (clone LO-MG1-2; Zymed, San Francisco, CA, USA) or rat anti-mouse IgG2a (clone LO-MG2a-3; Zymed) in PBS/BSA-Tween was added and incubated at $37^{\circ} \mathrm{C}$ for $2 \mathrm{~h}$. Between each step, wells were washed five times with PBS containing 0.02\% Tween-20 (PBS-Tween). Plates were developed at room temperature after the addition of $o$-phenylenediamine $(0.4 \mathrm{mg} / \mathrm{ml})$ and $\mathrm{H}_{2} \mathrm{O}_{2}(0.016 \%)$ in citrate-phosphate buffer ( $\mathrm{pH} 5 \cdot 0)$. Finally, $1 \mathrm{M}-\mathrm{H}_{2} \mathrm{SO}_{4}$ was added, and absorbance at $490 \mathrm{~nm}$ was measured with a microplate reader (model 550; Bio-Rad, Hercules, CA, USA).

\section{Profile analysis of faecal microbiota by polymerase chain reaction-denaturing gradient gel electrophoresis}

DNA was extracted from fresh faeces using a Fecal DNA Isolation Kit (MO Bio Laboratories, Carlsbad, CA, USA) according to the manufacturer's instructions. Faecal DNA samples were used as a template to amplify the fragments of $16 \mathrm{~S}$ rDNA with universal primers, F968-GC (CGC CCG GGG CGC GCC CCG GGC GGG GCG GGG GCA CGG GGG GAA CGC GAA GAA CCT TAC) and R1401 (CGG TGT GTA CAA GAC CC), and the denaturing gradient gel electrophoresis (DGGE) analysis of the amplicon was performed as previously described ${ }^{(35)}$. Briefly, PCR was performed in a reaction volume of $25 \mu \mathrm{l}$ that contained $500 \mathrm{nM}$ each of F968-GC and R1401, $1 \times$ PCR buffer, $0.2 \mathrm{mM}-\mathrm{dNTP}$ and $1.25 \mathrm{U}$ of Taq-HS polymerase (Takara, Otsu, Japan). The reaction conditions were $94^{\circ} \mathrm{C}$ for $5 \mathrm{~min}$, followed by thirty-five cycles of $94^{\circ} \mathrm{C}$ for $30 \mathrm{~s}, 56^{\circ} \mathrm{C}$ for $20 \mathrm{~s}$, and $68^{\circ} \mathrm{C}$ for $40 \mathrm{~s}$, and final extension at $68^{\circ} \mathrm{C}$ for $7 \mathrm{~min}$. The amplicons were analysed by DGGE on the DCode system (Bio-Rad) on an $8 \%$ polyacrylamide gel (dimensions $160 \times 180 \times 1 \mathrm{~mm}$ ) containing a $45 \%$ to $65 \%$ gradient of urea-formamide, where $100 \%$ was defined as $7 \mathrm{M}$-urea and $40 \%$ formamide. Electrophoresis was performed in Tris-acetate-EDTA (40 mM-2amino-2-hydroxymethyl-1,3-propanediol; $20 \mathrm{~mm}$-acetic acid; $1 \mathrm{mM}$-EDTA) at $80 \mathrm{~V}$ and $60^{\circ} \mathrm{C}$ for $16 \mathrm{~h}$. The gel was stained for $30 \mathrm{~min}$ in Tris-acetate-EDTA containing SYBR green I nucleic acid gel stain (Cambrex, Hopkinton, MA, USA) and photographed under a UV light transilluminator (model 400EX; Aisin Seiki, Kariya, Japan). Quantity One software (version 4.6.0; Bio-Rad) was used for band identification and normalisation of band patterns from DGGE gels. Subsequently, a dendrogram of the DGGE-band profile was constructed using Pearson's curve-based correlation and the 
unweighted pair-group method using the arithmetic average clustering method in Quantity One software as previously described $^{(36)}$.

Quantification of bifidobacteria and lactobacilli in faeces by real-time polymerase chain reaction

Amplification and detection of faecal DNA were performed with Smart Cycler II (Cepheid, Sunnyvale, CA, USA). Bifidobacterium genus-specific (forward, TCG CGT C(C/T)G GTG TGA AAG; reverse, CCA CAT CCA GC(A/G) TCC AC) ${ }^{(37)}$ and Lactobacillus genus-specific (forward, TGG AAA CAG (A/G)TG CTA ATA CCG; reverse, GTC CAT TGT GGA AGA TTC CC) ${ }^{(38)}$ primer pairs were used. Real-time PCR was performed in a reaction volume of $25 \mu \mathrm{l}$, containing 12.5 $\mu \mathrm{l}$ SYBR Premix Ex Taq (Takara), $200 \mathrm{~nm}$ each of the forward and reverse primers, and $1 \mu$ l faecal DNA samples. The reaction conditions were: $95^{\circ} \mathrm{C}$ for $30 \mathrm{~s}$, followed by forty-three cycles at $95^{\circ} \mathrm{C}$ for $5 \mathrm{~s}, 64^{\circ} \mathrm{C}$ for $15 \mathrm{~s}$, and $72^{\circ} \mathrm{C}$ for $15 \mathrm{~s}$ for the quantification of bifidobacteria, and $95^{\circ} \mathrm{C}$ for $30 \mathrm{~s}$, followed by forty-three cycles at $95^{\circ} \mathrm{C}$ for $5 \mathrm{~s}, 57^{\circ} \mathrm{C}$ for $20 \mathrm{~s}$, and $72^{\circ} \mathrm{C}$ for $15 \mathrm{~s}$ for the quantification of lactobacilli.

Bifidobacterium animalis (JCM $1190^{\mathrm{T}}$ ) and L. murinus (JCM 1717 ${ }^{\mathrm{T}}$ ) were cultured in De Man, Rogosa and Sharpe (MRS) broth (Becton Dickinson, Rockville, MD, USA) and the genomic DNA was extracted by Isoplant II (Wako Pure Chemical Ind., Osaka, Japan) according to the manufacturer's instructions. Fragments of $16 \mathrm{~S}$ rDNA were amplified by PCR with the Bifidobacterium or Lactobacillus genus-specific primer pairs listed above. The amplicons were purified by the GFX $^{\mathrm{TM}}$ PCR DNA and Gel Band Purification Kit (GE Healthcare Bioscience, Tokyo, Japan) and cloned in pGEMEasy $\mathrm{T}$ vectors (Promega, Madison, WI, USA). Transformation was performed with competent Escherichia coli XL-1 Blue cells and plated onto Luria-Bertani agar plates supplemented with ampicillin $(25 \mu \mathrm{g} / \mathrm{ml}), X-G a l(30 \mu \mathrm{g} / \mathrm{ml})$ and isopropyl $\beta$-D-1-thiogalactopyranoside $(20 \mu \mathrm{g} / \mathrm{ml})$ and incubated overnight at $37^{\circ} \mathrm{C}$. White transformants were picked and grown in Luria-Bertani broth. Plasmid DNA was extracted with QIAprep Spin Miniprep Kit (Qiagen, Germantown, MD, USA) and used as standards for real-time PCR.

Analysis of bifidobacterial diversity by polymerase chain reaction-denaturing gradient gel electrophoresis

Amplification of Bifidobacterium-genus specific 16S rDNA fragments and the DGGE analysis of the amplicon were performed as previously described ${ }^{(39)}$. Briefly, PCR was performed in a reaction volume of $25 \mu \mathrm{l}$, containing $500 \mathrm{nM}$ primers g-Bifid F (5' CTC CTG GAA ACG GGT GG) and g-Bifid R-GC (5' CGC CCG CCG CGC CCC GCG CCC GGC CCG CCG CCC CCG CCC CGT GGT TCT TCC CGA TAT CTA CA), $1 \times$ PCR buffer, $0 \cdot 2 \mathrm{mm-dNTP}$ and $1.25 \mathrm{U}$ of $\mathrm{Taq}$-HS polymerase (Takara). The reaction conditions were: $94^{\circ} \mathrm{C}$ for $5 \mathrm{~min}$, followed by thirty cycles at $94^{\circ} \mathrm{C}$ for $30 \mathrm{~s}, 62^{\circ} \mathrm{C}$ for $20 \mathrm{~s}$, and $72^{\circ} \mathrm{C}$ for $50 \mathrm{~s}$, and final extension at $72^{\circ} \mathrm{C}$ for $7 \mathrm{~min}$. The amplicons were analysed by DGGE as described above, except for using an $8 \%$ polyacrylamide gel containing a $45 \%$ to $55 \%$ gradient of urea-formamide. Fragments on the gel were cut out and amplified by PCR with g-Bifid primers. Amplicons were purified by the
GFX $^{\mathrm{TM}}$ PCR DNA and Gel Band Purification Kit (GE Healthcare Bioscience) and used for sequence analysis.

\section{Sequence analysis}

Purified PCR amplicons (40 ng) were used as a template, and the sequence reactions were performed with a DTCS sequence kit (Beckman Coulter Japan, Tokyo, Japan) according to the manufacturer's instructions with g-Bifid $\mathrm{F}$ and g-Bifid R-GC as the sequencing primers. Sequences were compared with those in the GenBank database with the BLAST $\mathrm{N}$ algorithm ${ }^{(40)}$.

\section{Statistical analysis}

Results are presented as mean values with their standard errors. The unpaired or paired $t$ test or Tukey-Kramer's test following one-way ANOVA was used to compare mean values. The correlation between the number of faecal bifidobacteria and ear swelling $24 \mathrm{~h}$ after challenge was assessed by Pearson's correlation method. Data analysis was performed with StatView for Macintosh (version 5.0; SAS Institute Inc., Cary, CA, USA). $P$ values less than 0.05 were considered statistically significant.

\section{Results}

Effect of fructo-oligosaccharides on the contact hypersensitivity response

Representative CHS responses of mice fed either FOS $(-)$ or FOS $(+)$ are shown in Fig. 1. The same experiments were repeated several times, and similar CHS responses were observed. Irrespective of the diet, ear swelling after DNFB challenge in non-immunised mice was routinely less than $10 \mu \mathrm{m}$ (data not shown). As shown in Fig. 1, $48 \mathrm{~h}$ after challenge, ear swelling reached a maximum and then decreased gradually in both the mice fed FOS $(-)$ and those fed FOS $(+)$. Ear swelling was significantly less in mice fed $\mathrm{FOS}(+)$ than in mice fed FOS $(-) 24 \mathrm{~h}$ after challenge, and the reductive effect of FOS intake was still observed even $48 \mathrm{~h}$ after challenge (Fig. 1). The area under the curve for ear swelling tended to be smaller in FOS $(+)$-fed mice when compared with $\operatorname{FOS}(-)$ fed mice $(13123$ (SEM 1835) $\mu \mathrm{m} \times 96 \mathrm{~h} v .16856$ (SEM 695) $\mu \mathrm{m} \times 96 \mathrm{~h})$.

In mice purchased from Japan Charles River, the levels of ear swelling were the same between FOS(-)- and FOS $(+)$ fed animals both $24 \mathrm{~h}$ (161.4 (SEM 16.4) v. 156.8 (SEM 16.8) $\mu \mathrm{m})$ and $48 \mathrm{~h}(190 \cdot 3(\operatorname{SEM} 7 \cdot 5) \quad v .196 .2(\mathrm{SEM} 13.6) \mu \mathrm{m})$ after challenge.

\section{Hapten-specific antibody responses}

There was no detectable hapten-specific antibody in the nonimmunised mice (data not shown). At $12 \mathrm{~d}$ after immunisation, both the mice fed FOS $(-)$ and the mice fed FOS $(+)$ produced detectable levels of hapten-specific IgG1 and IgG2a antibodies. Reciprocal $\log 2$ titres of hapten-specific IgG1 were the same between FOS $(-)$ - and FOS $(+)$-fed animals (11.0 (SEM 0.3) v. 11.3 (SEM 0.3)). Hapten-specific IgG2a titres of the FOS $(-)$ and $\operatorname{FOS}(+)$ groups were 6.3 (SEM 0.4) and 7.9 


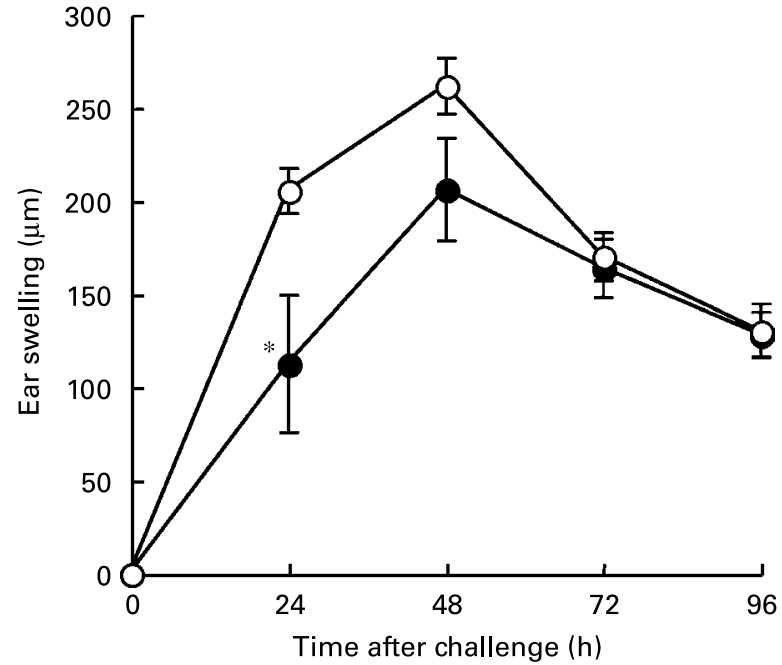

Fig. 1. Time course of ear swelling after 2,4-dinitrofluorobenzene (DNFB) challenge in mice fed no fructo-oligosaccharide (FOS $(-)$; O) and mice fed fructo-oligosaccharide $(\mathrm{FOS}(+) ; \bullet)$. Mice were fed the indicated diet for 3 weeks and then immunised epicutaneously with DNFB. Afterwards, the mice continued to receive the indicated diets. Mice were ear challenged with the hapten $5 \mathrm{~d}$ after immunisation. Ear thickness was measured before the challenge and 24, 48, 72 and $96 \mathrm{~h}$ after the challenge. Values are means for six or seven mice, with their standard errors represented by vertical bars. * Mean value was significantly different from the value for the mice fed FOS $(-)(P<0.05)$

(SEM 0.4), respectively. The serum level of hapten-specific $\operatorname{IgG} 2 \mathrm{a}$ in the $\mathrm{FOS}(+)$ group tended to be higher than that in the $\operatorname{FOS}(-)$ group.

Comparison of bacterial diversity with denaturing gradient gel electrophoresis

PCR-DGGE analyses for bacterial 16S rDNA extracted from fresh faeces were performed to compare the microbiota in FOS $(+)$-fed mice with the microbiota in FOS $(-)$-fed mice. A representative DGGE band profile is shown in Fig. 2 (A). The intensity and position of detected bands were subjected to cluster analysis (Fig. 2 (B)). The dendrogram shows two large clusters of FOS(+) and FOS(-) groups (Fig. 2 (B)).

\section{Quantification of faecal bifidobacteria and lactobacilli}

Quantification of faecal bifidobacteria and lactobacilli was performed by real-time PCR with Bifidobacterium and Lactobacillus genus-specific primers. Detectable levels of bifidobacteria were observed in all faecal DNA samples from $\mathrm{FOS}(+)$-fed mice, although they were observed in low levels in three out of six samples from FOS $(-)$-fed mice (Fig. 3 (A)). The faecal bifidobacteria level in FOS(+)-fed mice reached $1.6 \times 10^{5}$ copies $/ \mathrm{mg}$ faeces and was significantly higher than the level in FOS(-)-fed mice. The level of faecal lactobacilli in $\mathrm{FOS}(+)$-fed mice was not significantly different when compared with that of FOS(-)-fed mice (Fig. 3 (B)).

The numbers of bifidobacteria in the faecal samples were negatively correlated with the ear swelling $24 \mathrm{~h}$ after challenge (Fig. 4).

When mice purchased from Japan Charles River were used, neither FOS $(-)$-fed mice nor FOS $(+)$-fed mice had
(A)

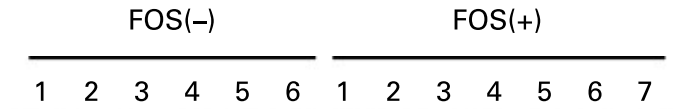

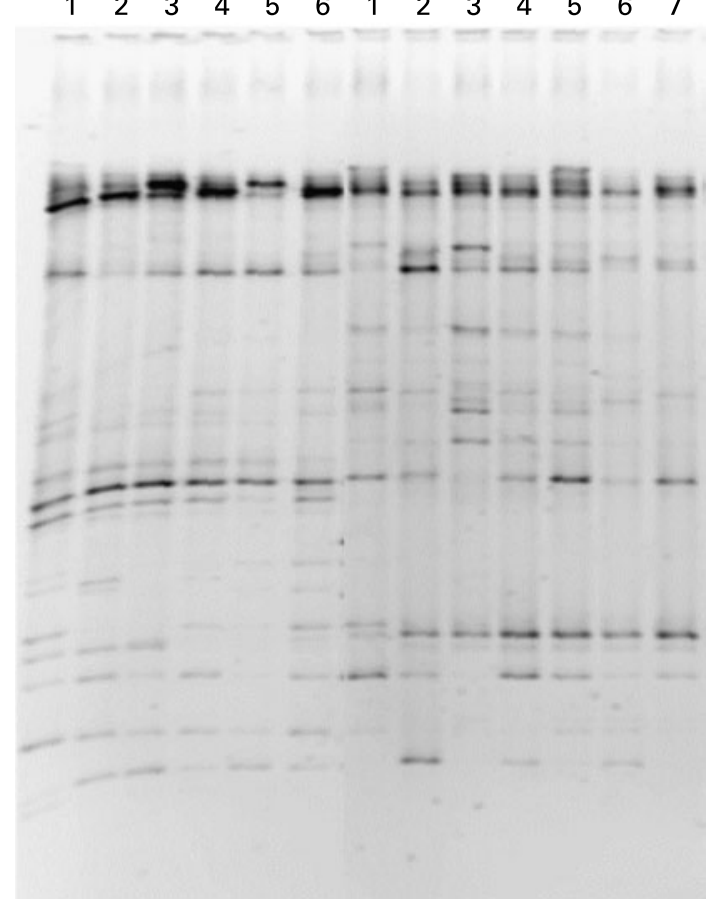

(B)

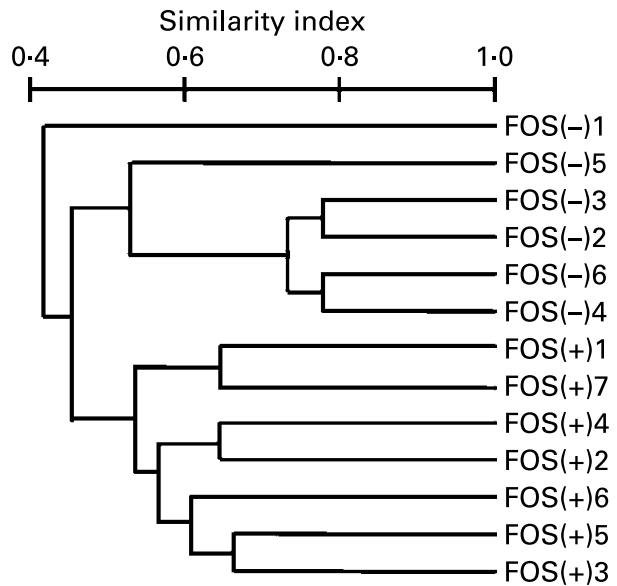

Fig. 2. PCR-denaturing gradient gel electrophoresis (DGGE) analysis of faecal microbiota based on 16S rDNA sequences in mice fed no fructo-oligosaccharide (FOS $(-))$ and mice fed fructo-oligosaccharide (FOS $(+))$. (A) SYBR green staining of PCR products separated by DGGE. (B) Similarities among DGGE band profiles of faecal bacteria of mice were calculated based on the position and intensity of bands, and the dendrogram of DGGE band profiles was constructed by the unweighted pair-group method using the arithmetic average clustering method. Distances are measured in arbitrary units.

detectable levels of bifidobacteria in faecal samples even 2 weeks after starting the test diets.

\section{Population profiling of bifidobacteria with denaturing gradient gel electrophoresis}

To characterise the population profiling of bifidobacteria in the faeces, PCR-DGGE with Bifidobacterium genus-specific primers was performed. DGGE band profiles are shown in Fig. 5. Only one band with high intensity was detected in 

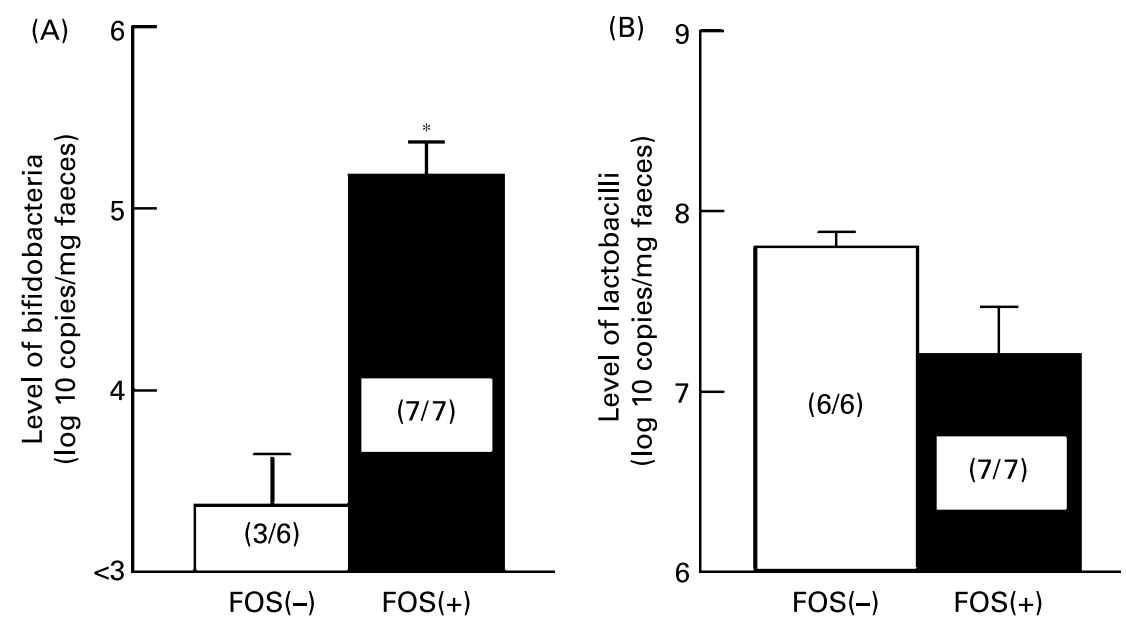

Fig. 3. Bacterial numbers of bifidobacteria (A) and lactobacilli (B) in the faeces of mice fed no fructo-oligosaccharide (FOS(-)) and mice fed fructo-oligosaccharide $($ FOS $(+))$. Bacterial numbers in the faeces were quantified by real-time PCR with genus-specific primers. PCR amplicons of genomic DNA from Bifidobacterium animalis $\left(\mathrm{JCM} 1190^{\top}\right)$ and Lactobacillus murinus $\left(\mathrm{JCM} 1717^{\top}\right)$ were ligated into pGEM-Easy vectors, and the resulting plasmids were used as standards. Values are means for six or seven mice, with their standard errors represented by vertical bars. Fractional values are the frequency of mice possessing detectable levels of bacteria. * Mean value was significantly different from the value for the mice fed FOS $(-)(P<0.05)$.

all mice fed $\mathrm{FOS}(+)$, while no detectable bands were observed in mice fed $\mathrm{FOS}(-)$, with one exception. The bands observed in $\mathrm{FOS}(+)$-fed mice were cut from the gel, and the DNA sequences were analysed. A BLAST search revealed that the sequences showed the highest similarity to B. pseudolongum $(99.8 \%, 486 / 487)$.

\section{Discussion}

Allergic contact dermatitis, which arises after CHS, is one of the most prevalent human skin diseases ${ }^{(1)}$. Avoidance of the causal allergen is not practical in the majority of the cases. Some food components ${ }^{(7-9)}$ and probiotic L. casei $^{(4)}$ reportedly reduce CHS in mice. We determined whether FOS influences DNFB-induced CHS in mice, the most widely used animal model for allergic contact dermatitis.

DNFB-induced ear swelling $24 \mathrm{~h}$ after the challenge was significantly less and the area under the curve for ear swelling tended to be smaller in mice fed $\mathrm{FOS}(+)$ when compared with those in mice fed FOS $(-)$ (Fig. 1), indicating that dietary FOS supplementation at a concentration of $5 \%$ retarded the DNFBinduced $\mathrm{CHS}$ response in $\mathrm{BALB} / \mathrm{c}$ mice. DNFB-induced CHS is a widely used model of allergic contact dermatitis and has been used for evaluating the anti-allergic effects of food components ${ }^{(7-9)}$. However, few reports have addressed CHS-reductive effects of non-digestive oligosaccharides, such as FOS.

It was previously reported that orally administered FOS affects intestinal microbiota, especially the growth of intestinal bifidobacteria ${ }^{(30-33)}$. Therefore, we hypothesised that the suppressive effect of FOS on CHS was associated with changes in intestinal microbiota. To test this hypothesis, cultivation-independent approaches based on bacterial 16S rDNA gene sequences were performed to study the bacterial composition of fresh faeces. A dendrogram of DGGE band profiles showed two large clusters of $\mathrm{FOS}(+)$ and $\mathrm{FOS}(-)$ groups (Fig. 2 (B)), clearly indicating that FOS administration changed the composition of intestinal microbiota. Additionally, real-time PCR analysis showed that the faecal bifidobacteria in the $\operatorname{FOS}(+)$-fed mice reached $1.6 \times 10^{5}$ copies $/ \mathrm{mg}$ faeces, although undetectable levels of bifidobacteria were observed in faeces from half of the FOS(-)-fed mice (Fig. 3 (A)). These results indicate that bifidobacteria, a minor community in the intestinal microbiota, proliferated by FOS administration. It is especially noteworthy that the numbers of faecal bifidobacteria were negatively correlated to the ear swelling $24 \mathrm{~h}$ after challenge (Fig. 4). These results suggest that suppression of DNFB-induced CHS by FOS administration is associated with increased numbers of faecal bifidobacteria in mice.

In the present study, mice were fed the synthetic diet to examine the effect of FOS supplementation. FOS supplementation reduced DNFB-induced CHS, which was associated with increased numbers of bifidobacteria. It has been reported that intestinal bifidobacteria proliferated when rats were fed a cereal-based commercial standard chow supplemented with

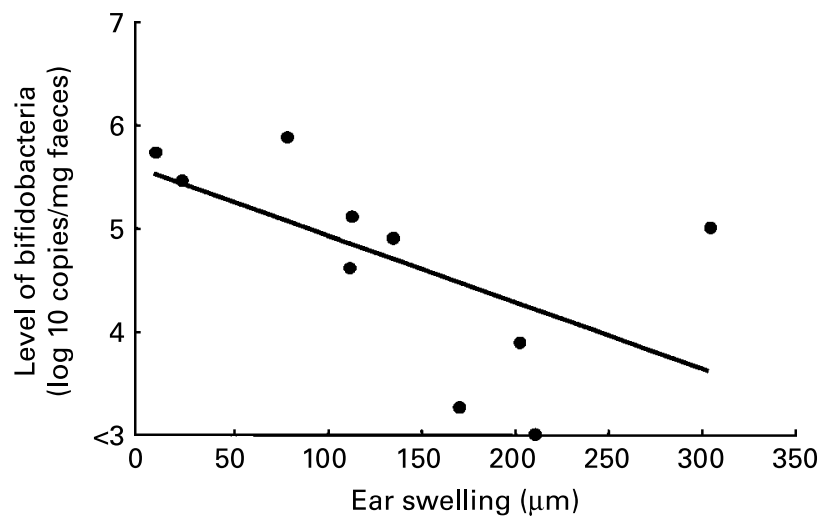

Fig. 4. Correlation between the numbers of bifidobacteria in faeces and ear swelling $24 \mathrm{~h}$ after 2,4-dinitrofluorobenzene challenge. The correlation $(R-0.585 ; P<0.05)$ was assessed by Pearson's correlation method. 


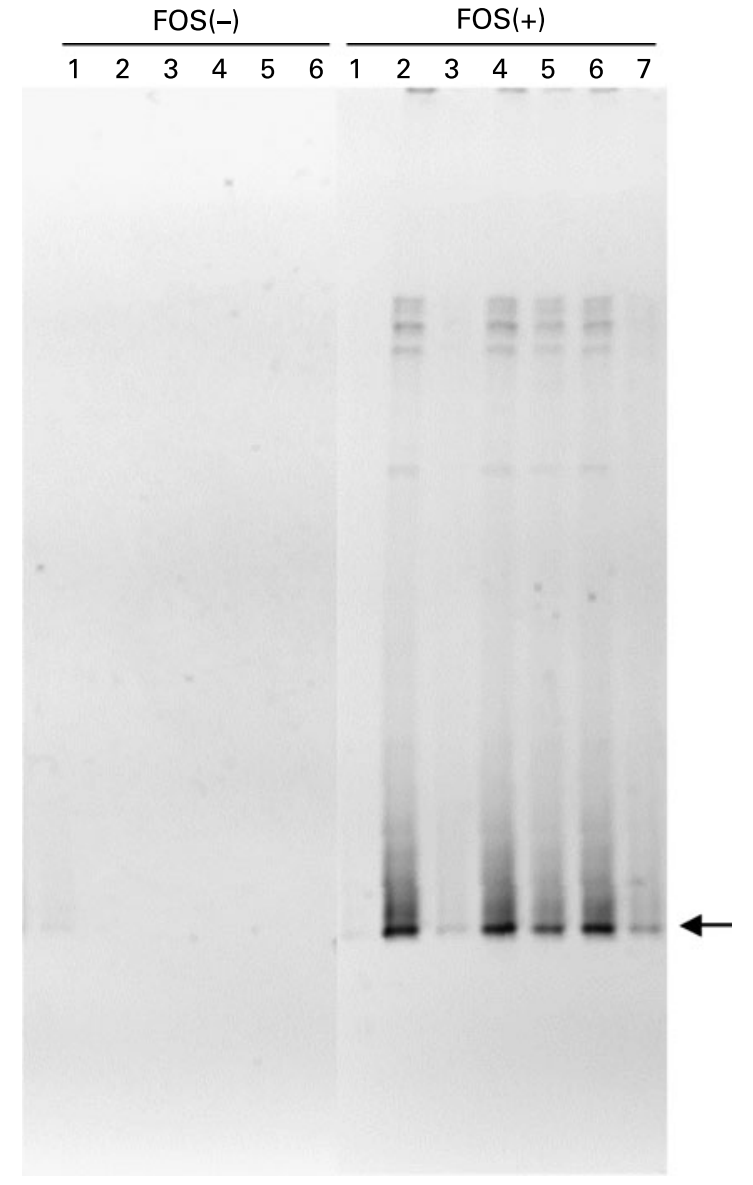

Fig. 5. PCR-denaturing gradient gel electrophoresis (DGGE) analysis of faecal microbiota based on 16S rDNA sequences in mice fed no fructo-oligosaccharide (FOS $(-))$ and mice fed fructo-oligosaccharide $(F O S(+))$. PCR amplicons by using Bifidobacterium genus-specific g-Bifid primers were separated by DGGE, and the gels were stained with SYBR green. The bands indicated $(\leftarrow)$ were amplified by $g$-Bifid primers, and their sequences were analysed.

$\mathrm{FOS}^{(41)}$. Although we have not determined whether FOS supplementation to a cereal-based diet influences the CHS reaction, it would be conceivable that the CHS-reducing effect of FOS is not specific to a synthetic diet.

Chapat et al. ${ }^{(4)}$ reported that oral administration of $L$. casei reduced the DNFB-induced CHS response in BALB/c mice. In the present study, however, FOS administration did not induce increased numbers of faecal lactobacilli (Fig. 3 (B)), suggesting that the suppressive effects of FOS on CHS are not associated with intestinal lactobacilli. Nagura et al. ${ }^{(42)}$ reported that caecal microbiota of BALB/c mice originating from two different breeders were different and that bifidobacteria were detected only in one breeding colony (from Japan SLC). Indeed, the present results showed that the numbers of bifidobacteria in the faeces of mice purchased from Charles River Japan, Inc., were less than the detection limit, even 2 weeks after FOS $(+)$ administration. In these mice, FOS $(+)$ did not reduce the DNFBinduced $\mathrm{CHS}$ response, although $\mathrm{BALB} / \mathrm{c}$ mice purchased from these breeders are considered to be genetically equivalent. These results also lend support to our hypothesis that increased numbers of bifidobacteria in the intestinal tract are responsible for the suppressive effect of FOS on the CHS response.
We next determined what species of bifidobacteria proliferated in mice fed FOS(+). PCR-DGGE with Bifidobacterium genus-specific primers revealed that administration of FOS induced proliferation of B. pseudolongum (Fig. 4). B. pseudolongum is the most predominant intestinal bifidobacteria in various mammals $^{(43)}$, and oral administration of this bacterial species decreases the frequency of diarrhoea in newborn calves and piglets ${ }^{(44)}$. However, few reports have addressed the immune-modulating effects of $B$. pseudolongum. In future experiments we will test whether oral administration of $B$. pseudolongum isolated from the faeces of mice fed FOS $(+)$ suppresses the CHS responses.

The cellular and molecular mechanisms involved in the suppressive effect of FOS on the CHS response are unclear. Although it is generally accepted that the DNFB-induced CHS response is independent of $\mathrm{CD}^{+} \mathrm{T}$-cell help ${ }^{(45,46)}$, the present study showed that epicutaneous immunisation induced the elevation of hapten-specific $\operatorname{IgG} 1$ and $\operatorname{IgG} 2 \mathrm{a}$ antibodies in sera. Chapat et al. ${ }^{(4)}$ demonstrated that oral administration of L. casei resulted in diminished levels of hapten-specific serum antibodies induced by skin inflammation. Thus, the probiotic exhibits potent immune-regulatory properties affecting both hapten-specific $\mathrm{CD} 4^{+}$helper $\mathrm{T}$ cells and $\mathrm{CD} 8^{+}$cytotoxic T-cell effectors of CHS. In contrast, the serum levels of hapten-specific IgG1 were the same in mice fed FOS(+) and mice fed FOS $(-)$ in the present study. Therefore, increased $B$. pseudolongum by FOS intake may not modulate $\mathrm{CD} 4^{+}$helper $\mathrm{T}$ cells. The reason for the upward trend in the serum hapten-specific IgG2a of FOS(+)-fed mice is not clear. However, this change might not be associated with the CHS-reductive effect of FOS, since the CHS response is independent of $\mathrm{CD} 4^{+} \mathrm{T}$ cells ${ }^{(45,46)}$.

In conclusion, the CHS response induced by skin application of DNFB was reduced by FOS supplementation in the diet. The numbers of intestinal bifidobacteria were increased by FOS, and B. pseudolongum was the most predominant bifidobacteria in the mice fed the $\mathrm{FOS}(+)$ diet. The severity of CHS was negatively correlated with the numbers of bifidobacteria; this finding strongly suggests that $B$. pseudolongum is responsible for the reductive effect of FOS consumption on the DNFB-induced CHS response.

\section{Acknowledgements}

The present study was partly supported by Special Coordination Funds for Promoting Science and Technology and by Grant-in-Aid for Scientific Research (B) from The Ministry of Education, Science, Sports and Culture of Japan. All authors (J. W., N. S., A. A. and K. S.) have no conflicts of interest.

\section{References}

1. Olmos A, Giner RM, Recio MC, Cardá-Nicolás JM \& Máñez S (2007) Effects of plant alkylphenols on cytokine production, tyrosine nitration and inflammatory damage in the efferent phase of contact hypersensitivity. $\mathrm{Br} J$ Pharmacol 152, 366-373.

2. Krasteva M, Kehren J, Ducluzeau MT, Sayag M, Cacciapuoti M, Akiba H, Descotes J \& Nicolas JF (1999) Contact dermatitis 
I. Pathophysiology of contact sensitivity. Eur J Dermatol 9 , $65-77$.

3. Saint-Mezard P, Berard F, Dubois B, Kaiserlian D \& Nicolas JF (2004) The role of $\mathrm{CD}^{+}{ }^{+}$and $\mathrm{CD} 8^{+} \mathrm{T}$ cells in contact hypersensitivity and allergic contact dermatitis. Eur J Dermatol 14, 131-138.

4. Chapat L, Chemin K, Dubois B, Bourdet-Sicard R \& Kaiserlian D (2004) Lactobacillus casei reduces $\mathrm{CD}^{+} \mathrm{T}$ cell-mediated skin inflammation. Eur J Immunol 34, 2520-2528.

5. Na K, Kim KE, Park ST \& Kim TY (2007) EC-SOD suppressed contact hypersensitivity in mice by impairing Langerhans cell migration. J Invest Dermatol 127, 1930-1937.

6. Xu H, Dilulio NA \& Fairchild RL (1996) T cell populations primed by hapten sensitization in contact sensitivity are distinguished by polarized patterns of cytokine production: interferon $\gamma$-producing ( $\mathrm{Tc} 1)$ effector $\mathrm{CD} 8^{+} \mathrm{T}$ cells and interleukin (IL) 4/IL-10-producing (Th2) negative regulatory $\mathrm{CD}^{+}$ T cells. J Exp Med 183, 1001-1012.

7. Tomobe YI, Morizawa K, Tsuchida M, Hibino H, Nakano Y \& Tanaka Y (2000) Dietary docosahexaenoic acid suppresses inflammation and immunoresponses in contact hypersensitivity reaction in mice. Lipids 35, 61-69.

8. Park HY, Park SH, Yoon HK, Han MJ \& Kim DH (2004) Antiallergic activity of $18 \beta$-glycyrrhetinic acid-3-O- $\beta$-D-glucuronide. Arch Pharm Res 27, 57-60.

9. Ishihara K, Oyamada C, Matsushima R, Murata M \& Muraoka $\mathrm{T}$ (2005) Inhibitory effect of porphyran, prepared from dried "Nori", on contact hypersensitivity in mice. Biosci Biotechnol Biochem 69, 1824-1830.

10. Mackie RI, Sghir A \& Gaskins HR (1999) Developmental microbial ecology of the neonatal gastrointestinal tract. Am J Clin Nutr 69, 1035S-1045S

11. Cebra JJ (1999) Influences of microbiota on intestinal immune system development. Am J Clin Nutr 69, 1046S-1051S.

12. Lanning D, Sethupathi P, Rhee KJ, Zhai SK \& Knight KL (2000) Intestinal microflora and diversification of the rabbit antibody repertoire. J Immunol 165, 2012-2019.

13. Holt PG \& Jones CA (2000) The development of the immune system during pregnancy and early life. Allergy 55, 688-697.

14. Moreau MC \& Corthier G (1988) Effect of the gastrointestinal microflora on induction and maintenance of oral tolerance to ovalbumin in $\mathrm{C} 3 \mathrm{H} / \mathrm{HeJ}$ mice. Infect Immun 56, 2766-2768.

15. Kiyono H, McGhee JR, Wannemuehler MJ \& Michalek SM (1982) Lack of oral tolerance in C3H/HeJ mice. J Exp Med 155, 605-610.

16. Sudo N, Sawamura S, Tanaka K, Aiba Y, Kudo C \& Koga Y (1997) The requirement of intestinal bacterial flora for the development of an $\mathrm{IgE}$ production system fully susceptible to oral tolerance induction. J Immunol 159, 1739-1745.

17. Guarner F \& Schaafsma GJ (1998) Probiotics. Int J Food Microbiol 39, 237-238.

18. Shornikova AV, Casas IA, Isolauri E, Mykkanen H \& Vesikari $\mathrm{T}$ (1997) Lactobacillus reuteri as a therapeutic agent in acute diarrhea in young children. J Pediatr Gastroenterol Nutr 24, 399-404.

19. Cruchet S, Obregon MC, Salazar G, Diaz E \& Gotteland M (2003) Effect of the ingestion of a dietary product containing Lactobacillus johnsonii La1 on Helicobacter pylori colonization in children. Nutrition 19, 716-721.

20. Kalliomaki M, Salminen S, Arvilommi H, Kero P, Koskinen P \& Isolauri E (2001) Probiotics in primary prevention of atopic disease: a randomized placebo-controlled trial. Lancet 357, 1076-1079.

21. Rosenfeldt V, Benfeldt E, Nielsen SD, Michaelsen KF, Jeppesen DL, Valerius NH \& Paerregaard A (2003) Effect of probiotic Lactobacillus strains in children with atopic dermatitis. $J$ Allergy Clin Immunol 111, 389-395.
22. Viljanen M, Savilahti E, Haahtela T, Juntunen-Backman K, Korpela R, Poussa T, Tuure T \& Kuitunen M (2005) Probiotics in the treatment of atopic eczema/dermatitis syndrome in infants: a double-blind placebo-controlled trial. Allergy 60, 494-500.

23. Rembacken BJ, Snelling AM, Hawkey PM, Chalmers DM \& Axon AT (1999) Non-pathogenic Escherichia coli versus mesalazine for the treatment of ulcerative colitis: a randomised trial. Lancet 354, 635-639.

24. Guslandi M, Mezzi G, Sorghi M \& Testoni PA (2000) Saccharomyces boulardii in maintenance treatment of Crohn's disease. Dig Dis Sci 45, 1462-1464.

25. Coppa GV, Bruni S, Soldi S \& Gabrielli O (2004) The first prebiotics in humans: human milk oligosaccharides. J Clin Gastroenterol 38, S80-S83.

26. Sonoyama K, Watanabe H, Watanabe J, Yamaguchi N, Yamashita A, Hashimoto H, Kishino E, Fujita K, Okada M, Mori S, Kitahata S \& Kawabata J (2005) Allergic airway eosinophilia is suppressed in ovalbumin-sensitized Brown Norway rats fed raffinose and $\alpha$-linked galactooligosaccharide. J Nutr 135, $538-543$.

27. Watanabe H, Sonoyama K, Watanabe J, Yamaguchi N, Kikuchi H, Nagura T, Aritsuka T, Fukumoto K \& Kasai T (2004) Reduction of allergic airway eosinophilia by dietary raffinose in Brown Norway rats. Br J Nutr 92, 247-255.

28. Stepans MB, Wilhelm SL, Hertzog M, Rodehorst TK, Blaney S, Clemens B, Polak JJ \& Newburg DS (2006) Early consumption of human milk oligosaccharides is inversely related to subsequent risk of respiratory and enteric disease in infants. Breastfeed Med 1, 207-215.

29. Cummings J \& MacFarlane G (2002) Gastrointestinal effects of prebiotics. Br J Nutr 87, Suppl. 2, S145-S151.

30. Van Loo J, Coussement P, de Leenheer L, Hoebregs H \& Smits $\mathrm{G}$ (1995) On the presence of inulin and oligofructose as natural ingredients in the Western diet. Crit Rev Food Sci Nutr 35, $525-552$.

31. Gibson GR, Beatty ER, Wang X \& Cummings JH (1995) Selective stimulation of bifidobacteria in the human colon by oligofructose and inulin. Gastroenterology 108, 975-982.

32. Langlands SJ, Hopkins MJ, Coleman N \& Cummings JH (2004) Prebiotic carbohydrates modify the mucosa associated microflora of the human large bowel. Gut 53, 1610-1616.

33. Ohta A, Uehara M, Sakai K, Takasaki M, Adlercreutz H, Morohashi T \& Ishimi Y (2002) A combination of dietary fructooligosaccharides and isoflavone conjugates increases femoral bone mineral density and equol production in ovariectomized mice. J Nutr 132, 2048-2054.

34. Reeves PG, Nielsen FH \& Fahey GC Jr (1993) AIN-93 purified diets for laboratory rodents: final report of the American Institute of Nutrition ad hoc writing committee on the reformulation of the AIN-76A rodent diet. J Nutr 123, 1939-1951.

35. Zoetendal EG, von Wright A, Vilpponen-Salmela T, Ben-Amor K, Akkermans ADL \& de Vos WM (2002) Mucosa-associated bacteria in the human gastrointestinal tract are uniformly distributed along the colon and differ from the community recovered from feces. Appl Eviron Microbiol 68, 3401-3407.

36. Wasaki J, Rothe A, Kania A, Neumann G, Römheld V, Shinano T, Osaki M \& Kandeler E (2005) Root exudation, phosphorus acquisition, and microbial diversity in the rhizosphere of white lupine as affected by phosphorus supply and atmospheric carbon dioxide concentration. $J$ Environ Qual 34, 2157-2166.

37. Rinttilä T, Kassinen A, Malinen E, Krogius L \& Palva A (2004) Development of an extensive set of $16 \mathrm{~S}$ rDNA-targeted primers for quantification of pathogenic and indigenous bacteria in faecal samples by real-time PCR. J Appl Microbiol 97, $1166-1177$. 
38. Byun R, Nadkarni MA, Chhour KL, Martin FE, Jacques NA \& Hunter N (2004) Quantitative analysis of diverse Lactobacillus species present in advanced dental caries. J Clin Microbiol 42, 3128-3136.

39. Vanhoutte T, De Preter V, De Brandt E, Verbeke K, Swings J \& Huys G (2006) Molecular monitoring of the fecal microbiota of healthy human subjects during administration of lactulose and Saccharomyces boulardii. Appl Environ Microbiol 72, 5990-5997.

40. Altschyl SF, Gish W, Miller W, Myers EW \& Lipman LJ (1990) Basic local alignment search tool. J Mol Biol 215, 403-410.

41. Kleessen B, Hartmann L \& Blaut M (2001) Oligofructose and long-chain inulin: influence on the gut microbial ecology of rats associated with human faecal flora. $B r J$ Nutr 86, $291-300$

42. Nagura T, Hachimura S, Kaminogawa S, Aritsuka T \& Ito K (2005) Characteristic intestinal microflora of specific pathogen-free mice bred in two different colonies and their influence on postnatal murine immunocyte profiles. Exp Anim 54, 143-148.

43. Gavini F, Delcenserie V, Kopeinig K, Pollinger S, Beerens H, Bonaparte C \& Upmann M (2006) Bifidobacterium species isolated from animal feces and from beef and pork meat. $J$ Food Prot 69, 871-877.

44. Abe F, Ishibashi N \& Shimamura S (1995) Effect of administration of bifidobacteria and lactic acid bacteria to newborn calves and piglets. $J$ Dairy Sci 78, 2838-2846.

45. Kehren J, Desvignes C, Krasteva M, Ducluzeau MT, Assossou O, Horand F, Hahne M, Kagi D, Kaiserlian D \& Nicolas JF (1999) Cytotoxicity is mandatory for CD8(+) T cell-mediated contact hypersensitivity. J Exp Med 189, 779-786.

46. Akiba H, Kehren J, Ducluzeau MT, Krasteva M, Horand F, Kaiserlian D, Kaneko F \& Nicolas JF (2002) Skin inflammation during contact hypersensitivity is mediated by early recruitment of $\mathrm{CD}^{+} \mathrm{T}$ cytotoxic 1 cells inducing keratibocyte apoptosis. J Immunol 168, 3079-3087. 